\title{
It's Time for Shared Decision Making and Person-Centred Care
}

\author{
Martin Härter ${ }^{1}$ (1)
}

Accepted: 3 October 2020 / Published online: 14 October 2020

(c) The Author(s) 2020

Dear Colleagues and Readers of this Special Issue,

It is a pleasure to congratulate the editors and authors of this special issue in The Patient. Following a call to all attendees, out of 39 submissions, patient partners and researchers have selected ten papers from the many scientific presentations of the 10th International Shared Decision Making (ISDM) Conference, which was held at the University Laval in Québec, Canada, from the 7th to the 10th of July 2019.

This 10th ISDM conference made a huge effort to involve patient partners on many levels as it complied with the Patients Included criteria. Patient partners have been present on all conference committees and participated actively in all decisions regarding the selection of speakers, abstracts and presentations. This has now translated into an editorial led by patient partners in this special issue.

The conference venue in Québec was also the host of the first General Assembly of the ISDM Society, which was founded in November 2018 in Hamburg (Germany) [1].

The society promotes shared decision making, "an approach where clinicians and patients share the best available evidence when faced with the task of making decisions, and where patients are supported to consider options, to achieve informed preferences" [2]. It is important to recognize that shared decision making is a process in which clinicians and patients at least work together to select tests, treatments, management or support packages, based on clinical evidence and the patients' values and informed preferences. Person-centeredness as a more general concept has also gained in importance, including policy and practice developments. A conceptual model based on a systematic review identified 16 dimensions of patientcentredness (e.g. the biopsychosocial perspective, access, coordination and continuity of care), which may allow different stakeholders to speak the same language [3, 4].

Martin Härter

m.haerter@uke.uni-hamburg.de

1 International Shared Decision Making Society E.V, Hamburg, Germany
We initiated this society to support a wide and evidencebased implementation of person- or patient-centred care and shared decision making in all care settings, for all types of patients, and in every country. Our vision is that healthcare decisions are well-informed by both research results and what matters most to patients and are based on collaboration between persons and their healthcare providers.

The ISDM Society is an international non-for-profit scientific association and is committed to increasing equity, diversity and inclusion among its members. Members are part of a unique network of international experts in person-centred care and shared decision making and are participating in regularly scheduled meetings and bi-annual conferences, which provide education and training on shared decision making and person-centred care [5]. Furthermore, members develop cooperative studies, create special interest groups and share ideas through a social networking platform [1].

\section{Declarations}

Funding Open Access funding enabled and organized by Projekt DEAL.

Conflict of Interest M. Härter is president of the International Shared Decision Making Society. He does not receive any compensation for this function.

Open Access This article is licensed under a Creative Commons Attribution-NonCommercial 4.0 International License, which permits any non-commercial use, sharing, adaptation, distribution and reproduction in any medium or format, as long as you give appropriate credit to the original author(s) and the source, provide a link to the Creative Commons licence, and indicate if changes were made. The images or other third party material in this article are included in the article's Creative Commons licence, unless indicated otherwise in a credit line to the material. If material is not included in the article's Creative Commons licence and your intended use is not permitted by statutory regulation or exceeds the permitted use, you will need to obtain permission directly from the copyright holder. To view a copy of this licence, visit http://creativecommons.org/licenses/by-nc/4.0/. 


\section{References}

1. https://www.isdmsociety.org. Accessed 11 Oct 2020.

2. Elwyn, et al. Shared decision making: a model for clinical practice. J Gen Intern Med. 2012;27(10):1361-7.

3. Scholl, et al. An integrative model of patient-centeredness-a systematic review and concept analysis. PLoS One. 2014;9:e107828.
4. Zeh et al. Assessing the relevance and implementation of patientcentredness from the patients' perspective in Germany. Results of a Delphi study. BMJ Open. 2019;9(12).

5. See information for the next conference in Kolding/Denmark under. www.isdm2021.com. Accessed 11 Oct 2020. 